\title{
Influence of Propolis on Hygiene, Gingival Condition, and Oral Microflora in Patients with Cleft Lip and Palate Treated with Fixed Orthodontic Appliances
}

\author{
Agnieszka Machorowska-Pieniążek, ${ }^{1}$ Tadeusz Morawiec, ${ }^{2}$ Anna Mertas, ${ }^{3}$ \\ Marta Tanasiewicz, ${ }^{4}$ Arkadiusz Dziedzic, ${ }^{4}$ and Wojciech Król ${ }^{3}$ \\ ${ }^{1}$ Department of Orthodontics, Medical University of Silesia in Katowice, Plac Traugutta 2, 41-800 Zabrze, Poland \\ ${ }^{2}$ Department of Oral Surgery, Medical University of Silesia in Katowice, Plac Akademicki 17, 41-902 Bytom, Poland \\ ${ }^{3}$ Department of Microbiology and Immunology, Medical University of Silesia in Katowice, Jordana 19, 41-808 Zabrze, Poland \\ ${ }^{4}$ Department of Conservative Dentistry with Endodontics, Medical University of Silesia in Katowice, Plac Akademicki 17, \\ 41-902 Bytom, Poland
}

Correspondence should be addressed to Agnieszka Machorowska-Pieniążek; agamach@onet.pl

Received 29 March 2013; Accepted 27 April 2013

Academic Editor: Ewelina Szliszka

Copyright (c) 2013 Agnieszka Machorowska-Pieniążek et al. This is an open access article distributed under the Creative Commons Attribution License, which permits unrestricted use, distribution, and reproduction in any medium, provided the original work is properly cited.

\begin{abstract}
The aim of this study was to evaluate the influence of $3 \%$ ethanol extract of propolis (EEP) on hygiene, gingival and microbiological status of oral cavity in patients with cleft lip and palate treated with fixed orthodontic appliances. The study included forty-one nonsyndromic complete unilateral of bilateral cleft lip and palate subjects with fixed appliance on at least 10 teeth. Twenty-one subjects were instructed to brush their teeth three times a day using toothpaste with propolis. Control group included twenty subjects who were asked to brush their teeth three times a day using a toothpaste without propolis. API, OPI, GI, and supragingival bacterial plaque were taken from each subject twice: baseline and after using the toothpaste for 35 days. The final examinations showed statistically significant decrease in OPI, GI, and the percentage of the Actinomyces spp. and Capnocytophaga spp. compared with baseline in propolis group subjects. The improvement in oral health in these patients confirms antibacterial, anti-inflammatory, and regenerative properties of propolis.
\end{abstract}

\section{Introduction}

The purpose of orthodontic therapy is to obtain a correct occlusion, harmonious facial contours, and efficient stomatognathic system with healthy periodontium and no dental caries. The presence of malocclusion, in particular teeth crowding accompanied by orthodontic appliances, leads to accumulation of dental plaque and problems with self-purification of teeth [1-5]. Orthodontic appliances modify oral environment affecting the amount, flow, and composition of saliva, including its $\mathrm{pH}$ and buffer ability, and induce occurrence of blood in saliva $[6,7]$. Furthermore, orthodontic therapy changes oral bacterial flora [8-10]. Brackets, bands, bars, wires, and other components of an orthodontic appliances may cause iatrogenic gingival swelling and are responsible for additional dental plaque retentions which are hardly accessible for mechanical cleaning of teeth [11-13]. Changes within oral cavity, occurring as a result of orthodontic treatment, may lead to diseases in dental hard tissues or in periodontium and mucosa. Therefore wearing fixed orthodontic appliances requires careful oral hygiene every day using brushes, irrigators, pastes, and mouthwashes. Pharmaceutical industry continually creates new chemical preparations and compounds to help maintaining proper oral hygiene. However, a great help comes from the nature as well.

Products obtained from plants or animals have been arousing much interest [14]. One of such products is propolis. Its beneficial properties were known and used already in the ancient times [15]. The Greek, Romans, and Egyptians used propolis to cure cuts, nonhealing wounds, or ulcers and to 
embalm corpses [16]. Propolis is produced by bees from plant buds or cracks in tree barks. It is then modified enzymatically and used to seal up their beehive doors, line beehive walls, or protect against microorganisms [17]. Propolis is a dense, adhesive mixture of wax and resin consisting of plant balsams, volatile oils, and chemically active compounds like phenolic acid or their esters, flavonoids (flavones, flavanones, and flavanols), aromatic alcohols and aldehydes, terpenes, fatty acids, $\beta$-steroids, mineral salts, and vitamins $[15,18]$. Propolis composition is varying and depends upon bee species, plant species, and climate [15, 17]. Propolis has strong bacteriocidal, antiviral, antiparasitic, fungicidal, and antioxidative properties. In vivo and in vitro studies confirmed anti-inflammatory properties of propolis and showed its strong immunomodulating effects [17-20]. Phenolic acids, aldehydes, ketones, and flavonoids inhibit classic and alternative complement activation and stimulate production of antibodies and INF $\gamma$ synthesis [21]. Prenylated p-coumaric acid activates macrophages, and caffeoylquinic acid derivatives stimulate their motility and spreading [22]. Furthermore, ethanol extract of propolis (EEP) was found to have an anti-inflammatory effect through IL-1 $\beta \mathrm{m}$ RNA expression inhibition and nitric oxide synthase (iONS) together with scavenging free radicals produced by neutrophils and macrophages [23-26]. Its antitumor effects were confirmed by many authors [27-31]. Considering the very wide range of therapeutic properties of propolis, a decision was taken to evaluate its influence on oral condition during orthodontic treatment.

The purpose of this paper is to evaluate the influence of $3 \%$ ethanol extract of propolis (EEP) on hygiene, gingival and microbiological status of oral cavity in patients with cleft lip and palate treated with fixed multiband-bracket appliances.

\section{Materials and Methods}

2.1. Clinical Examinations. The examinations were performed in Orthodontic Outpatient Clinic, Academic Center of Dentistry, and Specialist Medicine in Bytom, Poland. The study group consisted of 41 patients with nonsyndromic complete unilateral of bilateral cleft lip and palate (CLP) treated with fixed appliances. All patients had a fixed appliance on at least 10 teeth; they were in good general condition and had undergone no antibiotic therapy or surgical treatment of the face for at least one month before. Mean age was 12.37 years, and there were 17 girls and 24 boys (Table 1). The patients were divided randomly into two groups: propolis group (21 patients) and control group (20 patients). Propolis group patients were instructed to use CT gel, Carepolis toothpaste with propolis, and control group patients CC gel, Carepolis toothpaste without propolis. Dental toothpaste with CT propolis had 3\% content of ethanol extract of Brazilian propolis. Raw propolis was collected from the beekeeping section of the Seiri Alimentos Naturales, Brazil. Propolis samples were obtained from colonies of Africanized honeybees (Apis mellifera) in Minas Gerais State, Southeast Brazil, and collected in 2008 from the plant Baccharis dracunculifolia using plastic net. The unprocessed propolis was sent to the Nihon Natural Therapy Co., Ltd., Tokyo, Japan, for preparation of the EEP. The toothpastes with 3\% of EEP and without
TABLE 1: Demographic data.

\begin{tabular}{|c|c|c|c|c|c|c|c|}
\hline & \multirow[b]{2}{*}{ Mean } & \multicolumn{2}{|c|}{ Age } & \multicolumn{4}{|c|}{ Gender } \\
\hline & & Minimum & Maximum & $\begin{array}{l}\text { Std. } \\
\text { dev. }\end{array}$ & Girls & Boys & Total \\
\hline $\begin{array}{l}\text { Propolis } \\
\text { group }\end{array}$ & 12.43 & 9.8 & 16.4 & 1.60 & $\begin{array}{c}8 \\
19 \%\end{array}$ & $\begin{array}{c}13 \\
32 \%\end{array}$ & $\begin{array}{c}21 \\
51 \%\end{array}$ \\
\hline $\begin{array}{l}\text { Control } \\
\text { group }\end{array}$ & 12.53 & 9.7 & 18.2 & 2.75 & $\begin{array}{c}9 \\
22 \%\end{array}$ & $\begin{array}{c}11 \\
27 \%\end{array}$ & $\begin{array}{c}20 \\
49 \%\end{array}$ \\
\hline Total & 12.37 & 9.7 & 18.2 & 2.28 & $\begin{array}{c}17 \\
41 \%\end{array}$ & $\begin{array}{c}24 \\
59 \%\end{array}$ & $\begin{array}{c}41 \\
100 \%\end{array}$ \\
\hline
\end{tabular}

of EEP (placebo) were prepared in Nippon Zettoc Co., Ltd., Tokyo, Japan.

At baseline each patient received general instructions on the oral hygiene and was told to clean the teeth using Fones method, to use interdental brushes, and to clean the teeth three times daily using the toothpaste. The patients were informed about the purpose and method of the study and agreed to participate. The research programme was approved by the Bioethics Committee of the Silesian Chamber of Medicine (resolution no. 6/2010).

Oral hygiene and gingivae were evaluated, and a sample for microbiological examination was taken from each patient in both groups twice: at the baseline and after 35 days of using the paste. The examinations were performed by one investigator, with the same lighting, using a mirror, probe, and bead probe. Oral hygiene was examined using modified (without staining) Approximate Plaque Index (API) according to Lange and Orthodontic Plaque Index (OPI) for the segment of incisors and canines $[32,33]$.

Additionally, marginal gingivae was examined in each patient using gingival index (GI) according to Löe and Silness [34]. Furthermore, supragingival bacterial plaque was taken using a disposable microbiological swab set. Deposit was taken, using a sterile cotton swab rod, from gingival margin of the buccal surfaces of teeth 14 or 15 where orthodontic brackets were placed.

2.2. Microbiological Examinations. Samples for microbiological testing were inoculated on suitable culture media (Columbia agar, Schaedler K3 agar, and Sabauraud agar) from Biomerieux (Marcy l'Etoile, France). Aerobic bacteria were propagated on Columbia agar medium with $5 \%$ sheep blood at $37^{\circ} \mathrm{C}$. Anaerobic bacteria were propagated on Schaedler K3 medium with $5 \%$ sheep blood at $37^{\circ} \mathrm{C}$ in anaerobic conditions using Genbaganaer (Biomerieux, Marcy l'Etoile, France). Candida fungi were propagated on selective Sabouraud agar medium at $35^{\circ} \mathrm{C}$ in aerobic condition. Upon isolation and further culture of each microorganism, their species were identified with the help of the following reagent sets: Api $20 \mathrm{E}$, Api 20 NE, Api Candida (Biomerieux, Marcy l'Etoile, France), and ENTERO test $24 \mathrm{~N}$, NEFERM test $24 \mathrm{~N}$, STREPTO test 24, and ANAERO test 23 (Erba-Lachema, Brno, Czech Republic).

2.3. Data Analysis. Mean values \pm standard deviation of minimum and maximum values of each index were measured. 


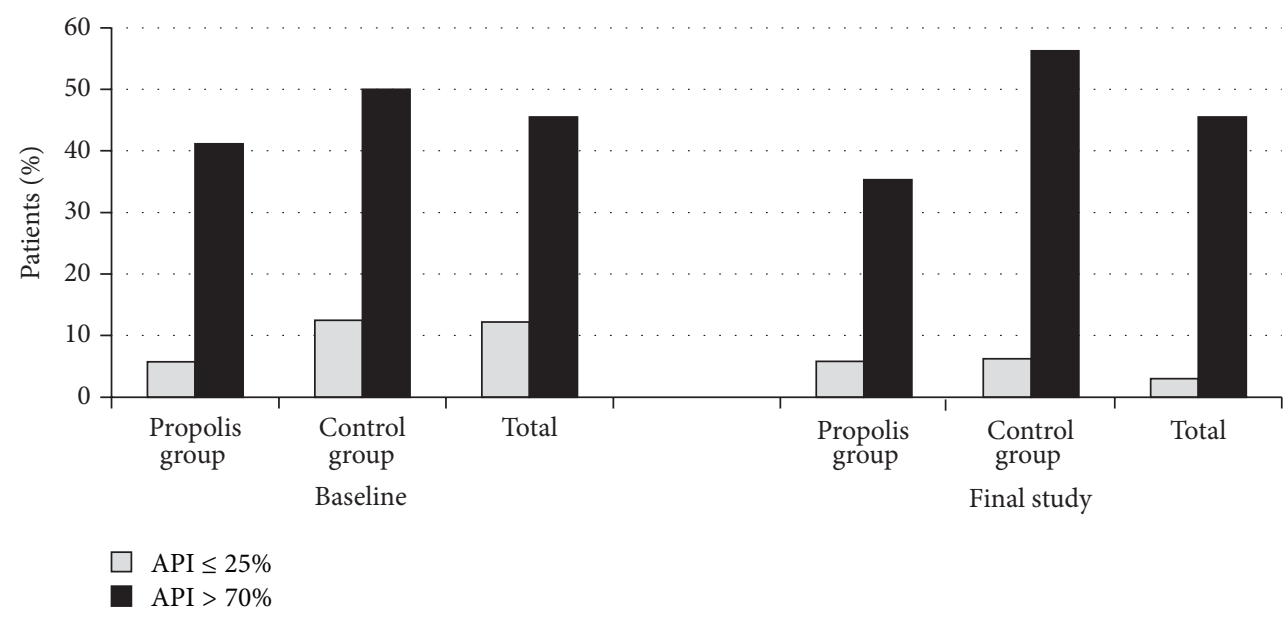

FIGURE 1: Percentage of patients distributed according to severity of API.

W. Shapiro-Wilk test was used to assess distribution normality of the variables. Analysis of the variables within the groups was done using $t$-test for dependent samples in case of normal distribution variables and Wilcoxon matched pairs test in absence of normal distribution. No homogeneous variance was shown (Levene's test: $P<.01$ ) for all variables. Comparison of the variables between propolis group and control group was performed using Tukey test for normal distribution variables and Mann-Whitney $U$ Test for nonparametric variables. All tests were significant with $P<.05$. Statistical analysis was done using Statistica v.8 software (Silesian Medical University, Katowice, Poland).

\section{Results}

3.1. Baseline. The examinations showed that mean values of all indices, that is, API, GI, and OPI, did not differ statistically between propolis group and control group at the first stage (Tables 2 and 3). Poor oral hygiene (API > 70\%) was found in $45.5 \%$ of the patients and very good hygiene (API $\leq 25 \%$ ) in $12.2 \%$ of the patients (Figure 1). Low amount of deposit around orthodontic brackets (OPI $\leq 2$ ) was shown in $28 \%$ of the patients, while high amount of deposit (OPI > 3) in $11.9 \%$ (Figure 2). Low gingival index, confirming good condition of gingivae $(\mathrm{GI}<2)$, was shown in $58 \%$ of the patients and high gingival index $(\mathrm{GI} \geq 2$ ) in $43 \%$ ( Figure 3 ).

3.2. Final Study. Second-stage examinations performed after 35 days showed differences between propolis group and control group. GI and OPI indices were statistically lower in propolis group as compared with control group $(P<.05)$. API showed no statistically significant difference between the groups.

3.3. Assessment of Propolis Influence on Dental Plaque and Gingivae. Using the paste without propolis (control group) or with propolis (propolis group) had no statistically significant influence on API $(P>$.05) (Table 3). However, statistically significant decreases were detected in propolis patients with reference to OPI and GI $(P<.05)$ (Table 3$)$. Furthermore the changes in API, OPI, and GI between the baseline and the final study in both groups were calculated, and a comparison between the propolis group and the control group group was made. API changes did not show a statistically significant difference between the groups (Table 3). However, GI and OPI changes were statistically different between propolis group and control group $(P<.05)$. Afterwards, the patients with extreme mean values of API, OPI, and GI were compared. The number of patients with very good oral hygiene and healthy gingivae (API $\leq 25 \%, \mathrm{OPI} \leq 2$, and $\mathrm{GI}<2$ ) and with poor hygiene and gingival inflammation (API $>70 \%$, OPI $>3$, and $\mathrm{GI} \geq 2$ ) was compared in propolis group and control group at the baseline and final stage (Figures 1-3). The greatest changes were in the propolis group. The percentage of patients with very good oral hygiene $(\mathrm{OPI}<2)$ and gingivae without bleeding $(\mathrm{GI}<2)$ was higher and the percentage of patients with gingival inflammation $(\mathrm{GI} \geq 2)$ was lower after using the toothpaste with propolis for 35 days (Figures 2 and 3 ).

3.4. Microbiological Findings. The bacteria most often found in oral swabs in both groups and at both stages of the study were Streptococcus spp. and Neisseria spp. (Table 4). No cariogenic Streptococcus mutans or Lactobacillus acidophilus were found in the samples.

Among bacteria particularly pathogenic for parodontal tissues, the presence of Actinomyces spp. together with Actinomyces israelii, Capnocytophaga spp., Fusobacterium, Bacteroides, and Eubacterium was predominant. Microbiological status was similar in both groups at the first stage of the study. However, the patients using propolis paste had statistically lower levels of Actinomyces spp. with Actinomyces israelii and Capnocytophaga spp. at the second stage of the study. A 10\% decrease in Actinomyces israelii level accompanied by an increase in Actinomyces spp. was found among control patients. The number of Candida albicans did not change (Table 4). 


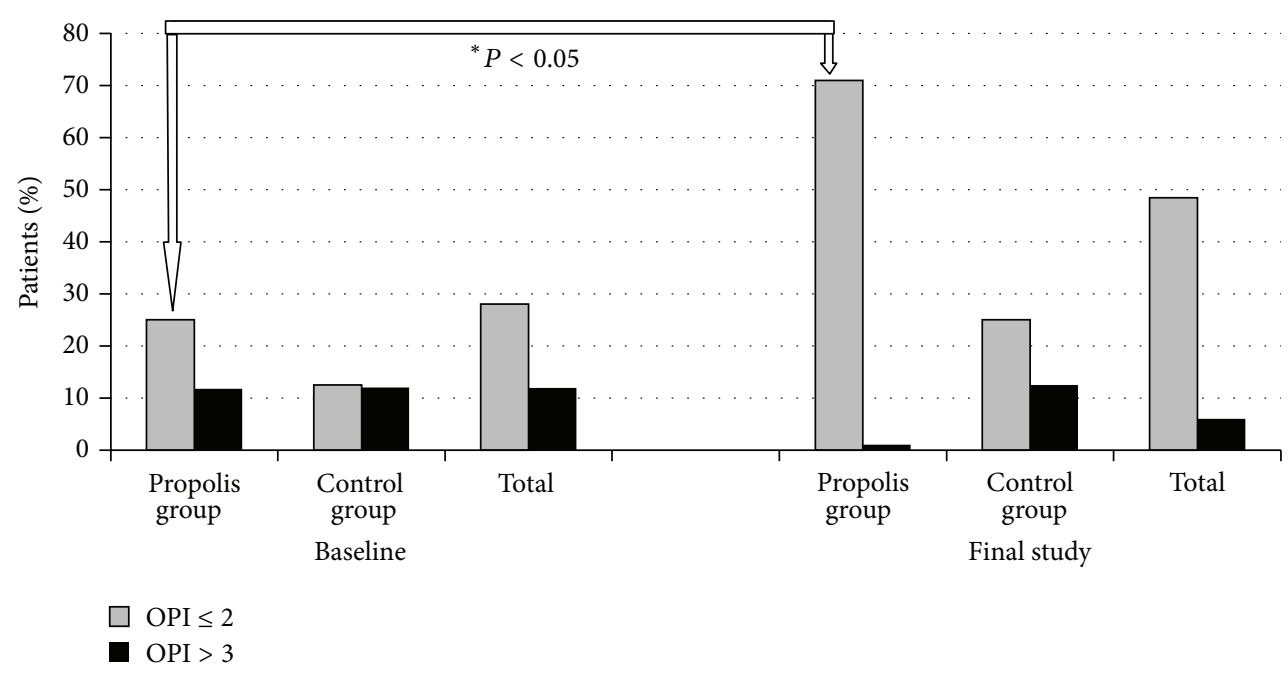

FIGURE 2: Percentage of patients distributed according to severity of OPI.

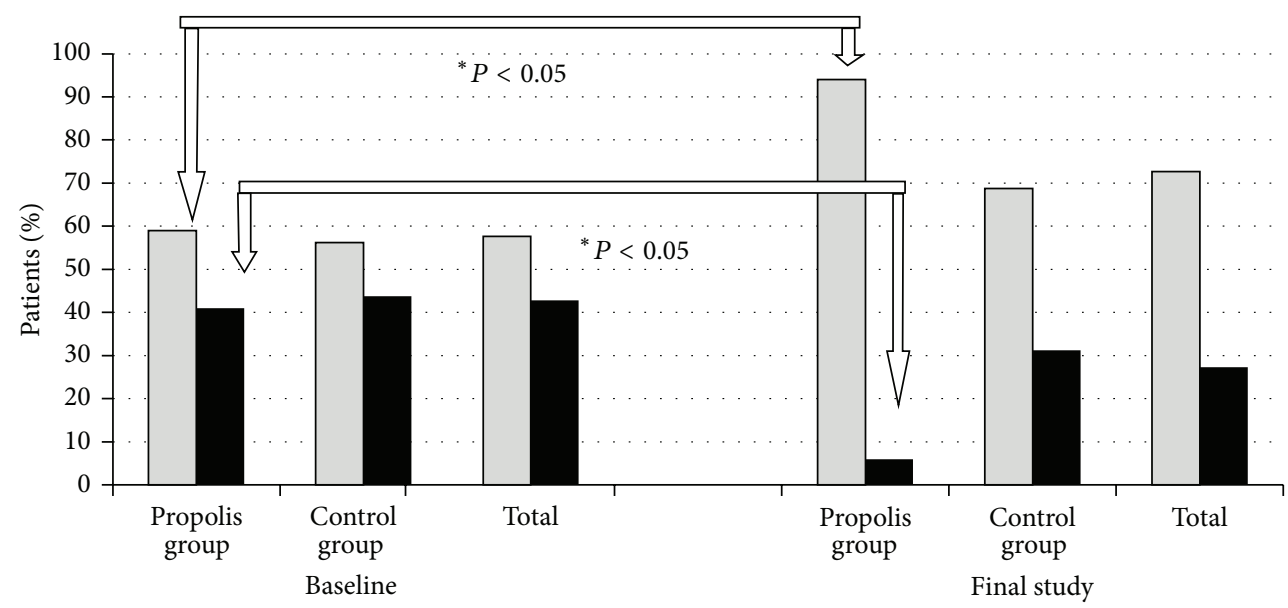

$\square \mathrm{GI}<2$

- $\mathrm{GI} \geq 2$

FIGURE 3: Percentage of patients distributed according to severity GI.

\section{Discussion}

Cleft lip and palate (CLP) is a fairly common congenital malformation within the head and neck, the frequency being 1.02.21 in 1000 live births [35]. Orthodontic care begins shortly after birth, taking many years and involving a variety of specialists in medicine and oral medicine [36]. Evaluation of oral hygiene and periodontal health in children and adults is an interesting subject for investigators and clinicians [36-48]. The authors of this paper decided to evaluate the influence of tooth cleaning with propolis paste on oral hygiene and oral microflora in patients with CLP.

The baseline examinations showed that most patients in propolis group and control group had poor oral hygiene (API > 70\%) with mean API of $64.31 \%$. The mean value of API was slightly higher in cleft palate/cleft lip palate patients studied by Schultes et al. with a tendency to poor oral hygiene [37]. On the other hand, very good oral hygiene (API) was shown in $12.5 \%$ of our patients at the baseline study. Slightly higher percentage of optimal oral hygiene was found by Stec et al. among oral cleft children in Łódź in active phase orthodontic treatment with the limit value for good hygiene (API) a little over $40 \%$, so higher than the percentage taken in this paper [38]. Low percentage of children with good oral hygiene and high mean plaque index, detected by our studies and by other authors as well, may be connected with different oral morphology and function in children with oral cleft as compared to children without any cleft. Oral deformity, manifested by nasal communications, frequent surgical procedures, scars within lips and palate, malocclusions, and disturbances in structure, morphology, number, or position of teeth, often accompanied by very long orthodontic treatment, makes oral hygiene maintaining extremely difficult [36]. Components of fixed appliances like 
TABLE 2: Summary scores of API, OPI, and GI in baseline and final study.

\begin{tabular}{|c|c|c|c|c|c|c|}
\hline & \multicolumn{3}{|c|}{ Baseline } & \multicolumn{3}{|c|}{ Final study } \\
\hline & API\% & OPI & GI & API\% & OPI & GI \\
\hline \multicolumn{7}{|l|}{$\begin{array}{l}\text { Propolis group } \\
N=21\end{array}$} \\
\hline Mean & 64.14 & 2.14 & 1.74 & 62.00 & 1.69 & 1.14 \\
\hline Minimum & 16.6 & 0.33 & 0.16 & 10.6 & 1.25 & 0.16 \\
\hline Maximum & 10.0 & 4.00 & 2.66 & 100.0 & 2.80 & 2.83 \\
\hline Std.dev. & 29.98 & 0.65 & 0.51 & 28.43 & 0.43 & 0.48 \\
\hline \multicolumn{7}{|l|}{$\begin{array}{l}\text { Control group } \\
N=20\end{array}$} \\
\hline Mean & 64.48 & 2.25 & 1.69 & 63.94 & 2.21 & 1.61 \\
\hline Minimum & 13.9 & 0.16 & 0.16 & 8.33 & 0.16 & 0.16 \\
\hline Maximum & 100.0 & 3.16 & 2.83 & 100.0 & 4.00 & 2.83 \\
\hline Std.dev. & 28.01 & 0.61 & 0.54 & 24.46 & 0.71 & 0.68 \\
\hline $\begin{array}{l}\text { Mean } \pm \text { std.dev. } \\
N=41\end{array}$ & $64.31 \pm 28.73$ & $2.19 \pm 0.68$ & $1.71 \pm 0.52$ & $63.97 \pm 26.44$ & $1.89 \pm 0.58$ & $1.37 \pm 0.58$ \\
\hline
\end{tabular}

TABLE 3: Statistical comparisons of API, OPI, and GI.

\begin{tabular}{|c|c|c|c|c|c|}
\hline & \multirow{3}{*}{\begin{tabular}{l}
\multicolumn{1}{c}{ A } \\
Intergroup \\
difference
\end{tabular}} & \multicolumn{2}{|c|}{ B } & \multirow{3}{*}{$\begin{array}{c}\text { C } \\
\text { Difference } \\
\text { test } \\
\text { Effect of } \\
\text { propolis }\end{array}$} \\
\hline & & & \multicolumn{2}{|c|}{ Intragroup difference } & \\
\hline & & & $\begin{array}{l}\text { Propolis } \\
\text { group }\end{array}$ & $\begin{array}{l}\text { Control } \\
\text { group }\end{array}$ & \\
\hline \multirow{2}{*}{ API } & Baseline & $0.503^{\mathrm{a}}$ & $0.871^{\mathrm{c}}$ & $0.871^{c}$ & $0.950^{\mathrm{b}}$ \\
\hline & final study & $0.850^{\mathrm{a}}$ & & & \\
\hline \multirow{2}{*}{ OPI } & Baseline & $0.137^{\mathrm{b}}$ & $0.012^{*, \mathrm{~d}}$ & $0.410^{\mathrm{d}}$ & $0.001^{*, \mathrm{~b}}$ \\
\hline & final study & $0.020^{*, \mathrm{~b}}$ & & & \\
\hline \multirow{2}{*}{ GI } & Baseline & $0.063^{\mathrm{a}}$ & $0.014^{*, \mathrm{c}}$ & $0.722^{c}$ & $0.002^{*, \mathrm{~b}}$ \\
\hline & final study & $0.034^{*, \mathrm{a}}$ & & & \\
\hline
\end{tabular}

A: differences between the propolis group and the control group; B: differences between baseline and final study; C: statistical changes between baseline and final study in the propolis group compared with the control group. ${ }^{\mathrm{a}}$ Tukey test, ${ }^{\mathrm{b}}$ Mann-Whitney $U$ Test, ${ }^{\mathrm{c}} t$-test for dependent samples, and ${ }^{\mathrm{d}}$ Wilcoxon matched pairs test; ${ }^{*}$ significance $(P<.05)$.

bands or other enamel bonded attachments like brackets are also a problem to oral hygiene $[11,12]$. Klukowska et al. reported 2-3 times higher level of plaque in patients wearing orthodontic appliances as compared to patients without treatment [39].

OPI used in our study is particularly recommended to assess the level of plaque in patients wearing fixed appliances because its value depends on the presence of dental deposits on each tooth surface adjacent to the bracket base [33]. We used a modified OPI only for anterior segment, and we demonstrated that the baseline value of this index was 2.1 in both groups, indicating a moderately good oral hygiene. No reports on this index, with reference to patients with oral clefts, have been found in the available literature so far.

Gingivae condition was examined using GI, and its baseline mean value was 1.71 . Slightly higher value of this index was reported by Costa et al. for children with oral clefts [40]. Their value was statistically higher compared to children without clefts. Our examinations showed that $58 \%$ of the patients in both groups had good gingival state, whereas $43 \%$ had gingival inflammation. Similar results were received by Perdikogianni et al. and showed that children with cleft lip and palate had moderate gingival inflammation, with no statistical difference compared to children with no cleft [41].

Final-stage examinations showed that mean value of API was slightly lower in both groups. OPI and GI values were statistically lower in propolis group, after using propolis toothpaste for 35 days, as compared to the baseline values. Similar results were received by Dodwad and Kukreja in their study on five-day use of propolis mouth wash [42]. Tanasiewicz et al. demonstrated a beneficial effect of propolis in patients with healthy periodontium and those with periodontitis [43]. Beneficial influence of propolis on periodontium was also demonstrated by Botushanov et al. who studied 42 patients cleaning their teeth with silicate toothpaste with extract from propolis for 28 days [44]. Pereira et al. assessed gingival index and plaque index in patients who had been using alcohol-free mouthwash containing 5.0\% Brazilian green propolis for 45 and 90 days. On day 45 and on day 90 the gingival index and plaque index had statistically higher values compared to the baseline [45].

The influence of propolis on patients showing extreme GI values was also studied in both groups. In this study statistical reduction of percentage of patients using propolis toothpaste were found to have gingival inflammation. Similar situation was noted in control group, but decrease in gingival inflammation cases was not statistically significant. Another interesting observation was that gingivae condition became much better with no significant decrease in dental plaque amount expressed by API. Similar changes were reported by Stec et al. who demonstrated an absence of relationship between API and gingivae condition [38]. It is important to realize that API only gives information about the presence or 
TABLE 4: Frequency of bacterial species in propolis group and control group in baseline and final study.

\begin{tabular}{|c|c|c|c|c|}
\hline \multirow{3}{*}{ Bacterial species } & \multicolumn{2}{|c|}{ Propolis group $N=21$} & \multicolumn{2}{|c|}{ Control group $N=20$} \\
\hline & Baseline & Final study & Baseline & Final study \\
\hline & $\%$ & $\%$ & $\%$ & $\%$ \\
\hline \multicolumn{5}{|l|}{ Gram+ } \\
\hline \multicolumn{5}{|l|}{ Facultative anaerobic } \\
\hline Streptococcus spp. & 90.4 & 85.7 & 90.0 & 100.0 \\
\hline S. mitis & 57.10 & 61.9 & 55.0 & 60.0 \\
\hline S. salivarius & 19.04 & 9.52 & 25.0 & 20.0 \\
\hline S. vestibularis & 19.04 & 9.52 & 20.0 & 30.0 \\
\hline S. oralis & 19.04 & 9.52 & 15.0 & 10.0 \\
\hline S. sanguinis & 0.00 & 9.52 & 10.0 & 20.0 \\
\hline Actinomyces spp. & 28.57 & $9.52^{*}$ & 30.0 & 40.0 \\
\hline Actinomyces israelii & 19.00 & $0.00^{*}$ & 15.0 & 25.0 \\
\hline \multicolumn{5}{|l|}{ Anaerobic } \\
\hline Bifidobacterium spp. & 23.80 & 23.80 & 30.0 & 25.0 \\
\hline Eubacterium spp. & 4.76 & 0.00 & 10.0 & 10.0 \\
\hline Gemella morbillorum & 9.52 & 0.00 & 15.0 & 15.0 \\
\hline Clostridium spp. & 14.28 & 9.52 & 0.00 & 0.00 \\
\hline \multicolumn{5}{|l|}{ Gram- } \\
\hline \multicolumn{5}{|l|}{ Facultative anaerobic } \\
\hline Neisseria spp. & 90.4 & 95.2 & 95.0 & 90.0 \\
\hline Capnocytophaga spp. & 19.04 & $0.00^{*}$ & 15.0 & 10.0 \\
\hline Enterobacter kobei & 0.00 & 0.00 & 5.0 & 5.0 \\
\hline Klebsiella pneumoniae & 0.00 & 0.00 & 10.0 & 10.0 \\
\hline Klebsiella oxytoca & 4.76 & 9.52 & 5.0 & 10.0 \\
\hline \multicolumn{5}{|l|}{ Anaerobic } \\
\hline Veillonella spp. & 23.80 & 23.80 & 20.0 & 25.0 \\
\hline Mitsuokella spp. & 9.52 & 4.76 & 0.00 & 0.00 \\
\hline Bacteroides spp. & 9.52 & 9.52 & 0.0 & 10.0 \\
\hline Fusobacterium spp. & 14.28 & 0.00 & 25.0 & 30.0 \\
\hline \multicolumn{5}{|l|}{ Candida } \\
\hline Candida albicans & 9.52 & 9.52 & 15.0 & 15.0 \\
\hline
\end{tabular}

${ }^{*}$ Significance $P<.05$ compared with baseline.

absence of dental plaque with no assessment of its amount and location.

In final stage of the study OPI showed statistically lower levels than those in the baseline in patients using propolis toothpaste. Other authors also demonstrated a beneficial influence of propolis on the plaque index (PI) [42-44].

Bacterial flora harvested during first-stage examinations in both groups consisted largely of Gram-negative cocci, chiefly Neisseria spp., and Gram-positive facultative anaerobes, including chiefly Streptococcus spp. and Actinomyces spp. Similar results were received by Ritz who demonstrated variable composition of the plaque in accordance with its maturity and predominance of Neisseria in the earliest stage of bacterial flora formation [46]. Coexistence of Streptococcus spp. and Actinomyces spp. is widely reported in the available literature. Perdikogianni et al. detected high mutual proportion of Streptococcus and Actinomyces in their study on frequency of bacteria in patients with cleft lip and/or palate [41]. Aas et al. demonstrated coexistence of both species in the early phase of dental caries, being to a great extent responsible for originating the process [47]. Cisar et al. revealed the adhesion-receptor mechanism of both bacteria which populate the oral environment through coaggregation [48]. Absence of Streptococcus mutans and Lactobacillus acidophilus with predominance of Streptococcus spp. and Actinomyces spp. in our study material confirms the "ecological hypothesis of dental plaque" suggesting that plaque status is a result of an interaction between many different bacterial species currently existing in oral cavity whereas its composition is variable and depends on environmental factors [49]. Munson et al. detected, based on their examinations, the permanent presence of only one or two Lactobacillus spp. in each lesion in a subject, and Aas et al. found Streptococcus mutans in only 10-20\% of their patients with severe caries $[47,50]$. The microbiological cultures detected absence of A. actinomycetemcomitans in CLP children of this study, but multiform Gram-negative anaerobic bacteria with many pathogens were likely to cause 
periodontitis. This result was in agreement with the studies on microflora in subjects with oral clefts reported by other investigators $[40,41]$. Also, the investigators demonstrated that the composition of oral microflora was individually depending on the sample site, current health state, or tooth condition [9, 11, 47-50]. Ristic et al. indicated lower level of bacterial flora in the region of molars in patients wearing fixed orthodontic appliances, and Alexander detected statistically more cases of gingivitis around molars with orthodontic bands that were around enamel bonded attachments $[9,11]$.

Final microbiological analysis of bacterial flora in patients using propolis toothpaste revealed the greatest decrease in frequency of Gram-positive facultative anaerobic cocci and Gram-positive facultative anaerobic rods. This result may indicate antibacterial properties of propolis used for everyday oral hygiene and confirmed by in vitro examinations [51-54]. The mechanism of antibacterial effects of propolis is complex and not quite clear [51]. Mirzoeva et al. have demonstrated that the effects of propolis are species-dependent and strongly related to disintegration of bacterial cell membrane through an increase in its permeability by ions. As a result a bacterial cell may lose its membrane potential thus also losing motility and virulence. Such effects are found with flavonoid and cinnamic components of propolis [52]. Other investigators suggest that antibacterial properties of propolis may be related to some additional mechanisms like inhibition of glucosyltransferase synthesis and production of polysaccharide by Streptococcus [52-54]. It is important to note that a decrease in the number of bacteria is accompanied by lower severity of gingivitis in patients using propolis. No significant changes in the number of bacteria and no improvement in the condition of gingivae or hygiene were noted among patients using toothpaste without propolis.

\section{Conclusion}

Results of the study examinations and tests reveal a significant improvement in gingivae, a lower level of dental plaque, and a decrease in frequency of Gram-positive rods in children with cleft lip and palate after using propolis toothpaste. The improvement in oral health in these patients confirms antibacterial, anti-inflammatory, and regenerative properties of propolis.

\section{Conflict of Interests}

The authors declare no conflict of interests.

\section{Acknowledgment}

The authors thank Mr. Rindai Yamamoto the president of Nihon Natural Foods Co., Ltd. (Tokyo, Japan), for the sample of Brazilian green propolis and technical support.

\section{References}

[1] J. van Gastel, M. Quirynen, W. Teughels, and C. Carels, "The relationships between malocclusion, fixed orthodontic appliances and periodontal disease. A review of the literature," Australian Orthodontic Journal, vol. 23, no. 2, pp. 121-129, 2007.
[2] A. Diamanti-Kipioti, F. A. Gusberti, and N. P. Lang, "Clinical and microbiological effects of fixed orthodontic appliances," Journal of Clinical Periodontology, vol. 14, no. 6, pp. 326-333, 1987.

[3] B. Liśniewska-Machorowska, H. Książek-Bąk, and A. Pisulska-Otremba, "Ocena stanu przyzębia dzieci leczonych szczękowo-ortopedycznie $\mathrm{z}$ uwzględnieniem wad zgryzu, grup zębowych i okresu stosowania aparatu," Czasopismo Stomatologiczne, vol. 42, no. 9, pp. 568-572, 1990 (Polish).

[4] H. Książek-Bąk, B. Liśniewska-Machorowska, and A. PisulskaOtremba, "Ocena stanu przyzębia u dzieci leczonych i nieleczonych ortodontycznie," Czasopismo Stomatologiczne, vol. 44, no. 3, pp. 191-197, 1991 (Polish).

[5] V. Krishnan, R. Ambili, Z. Davidovitch, and N. C. Murphy, "Gingiva and orthodontic treatment," Seminars in Orthodontics, vol. 13, no. 4, pp. 257-271, 2007.

[6] E. Lara-Carrillo, N. M. Montiel-Bastida, L. Sánchez-Pérez, and J. Alanís-Tavira, "Effect of orthodontic treatment on saliva, plaque and the levels of Streptococcus mutans and Lactobacillus," Medicina Oral, Patologia Oral y Cirugia Bucal, vol. 15, no. 6, pp. e924-e929, 2010.

[7] A. Kornet, D. Maciejak, D. Olczak-Kowalczyk, M. Dąbkowska, J. Cieślik, and M. Zadurska, "Assessment of the buffer capacity of saliva and oral flora in patients with oligodontia of permanent teeth-preliminary report," Forum Ortodontyczne, vol. 8, no. 4, pp. 173-182, 2012.

[8] E. J. Sallum, D. F. Nouer, M. I. Klein et al., "Clinical and microbiologic changes after removal of orthodontic appliances," American Journal of Orthodontics and Dentofacial Orthopedics, vol. 126, no. 3, pp. 363-366, 2004.

[9] M. Ristic, M. Vlahovic Svabic, M. Sasic, and O. Zelic, "Clinical and microbiological effects of fixed orthodontic appliances on periodontal tissues in adolescents," Orthodontics \& Craniofacial Research, vol. 10, no. 4, pp. 187-195, 2007.

[10] S. Petti, E. Barbato, and A. Simonetti D’Arca, "Effect of orthodontic therapy with fixed and removable appliances on oral microbiota: a six-month longitudinal study," New Microbiologica, vol. 20, no. 1, pp. 55-62, 1997.

[11] S. A. Alexander, "Effects of orthodontic attachments on the gingival health of permanent second molars," American Journal of Orthodontics and Dentofacial Orthopedics, vol. 100, no. 4, pp. 337-340, 1991.

[12] M. C. Huser, P. C. Baehni, and R. Lang, "Effects of orthodontic bands on microbiologic and clinical parameters," American Journal of Orthodontics and Dentofacial Orthopedics, vol. 97, no. 3, pp. 213-218, 1990.

[13] F. Atassi and F. Awartani, "Oral hygiene status among orthodontic patients," The Journal of Contemporary Dental Practice, vol. 11, no. 4, pp. 25-32, 2010.

[14] E. A. Palombo, "Traditional medicinal plant extracts and natural products with activity against oral bacteria: potential application in the prevention and treatment of oral diseases," Evidence-based Complementary and Alternative Medicine, vol. 2011, Article ID 680354, 15 pages, 2011.

[15] W. Więckiewicz, M. Miernik, M. Więckiewicz, and T. Morawiec, "Does propolis help to maintain oral health?" Evidence-Based Complementary and Alternative Medicine, vol. 2013, Article ID 351062, 8 pages, 2013.

[16] G. A. Burdock, "Review of the biological properties and toxicity of bee propolis (propolis)," Food and Chemical Toxicology, vol. 36, no. 4, pp. 347-363, 1998. 
[17] J. M. Sforcin, "Propolis and the immune system: a review," Journal of Ethnopharma-Cology, vol. 113, no. 1, pp. 1-14, 2007.

[18] V. S. Bankova, S. S. Popov, and N. L. Marekov, "A study on flavonoids of propolis," Journal of Natural Products, vol. 46, no. 4, pp. 471-474, 1983.

[19] K. W. Cheung, D. M. Y. Sze, W. K. Chan, R. X. Deng, W. Tu, and G. C. F. Chan, "Brazilian green propolis and its constituent, Artepillin C inhibits allogeneic activated human CD4 T cells expansion and activation," Journal of Ethnopharmacology, vol. 138, no. 2, pp. 463-471, 2011.

[20] G. Fischer, F. R. Conceição, F. P. L. Leite et al., "Immunomodulation produced by a green propolis extract on humoral and cellular responses of mice immunized with SuHV-1," Vaccine, vol. 25, no. 7, pp. 1250-1256, 2007.

[21] N. D. Ivanovska, V. B. Dimov, S. Pavlova, V. S. Bankova, and S. S. Popov, "Immunomodulatory action of propolis. V. Anticomplementary activity of a water-soluble derivative," Journal of Ethnopharmacology, vol. 47, no. 3, pp. 135-143, 1995.

[22] T. Tatefuji, N. Izumi, T. Ohta, S. Arai, M. Ikeda, and M. Kurimoto, "Isolation and identification of compounds from Brazilian propolis which enhance macrophage spreading and mobility," Biological and Pharmaceutical Bulletin, vol. 19, no. 7, pp. 966-970, 1996.

[23] M. Blonska, J. Bronikowska, G. Pietsz, Z. P. Czuba, S. Scheller, and W. Krol, "Effects of ethanol extract of propolis (EEP) and its flavones on inducible gene expression in J774A.1 macrophages," Journal of Ethnopharmacology, vol. 91, no. 1, pp. 25-30, 2004.

[24] W. Król, J. Shani, Z. Czuba, and S. Scheller, "Modulating luminol-dependent chemiluminescence of neutrophils by flavones," Zeitschrift Für Naturforschung C, vol. 47, no. 11-12, pp. 889-892, 1992.

[25] H. Li, A. Kapur, J. X. Yang et al., "Antiproliferation of human prostate cancer cells by ethanolic extracts of Brazilian propolis and its botanical origin," International Journal of Oncology, vol. 31, no. 3, pp. 601-606, 2007.

[26] A. P. Bazo, M. A. M. Rodrigues, J. M. Sforcin, J. L. V. De Camargo, L. R. Ribeiro, and D. M. F. Salvadori, "Protective action of propolis on the rat colon carcinogenesis," Teratogenesis Carcinogenesis and Mutagenesis, vol. 22, no. 3, pp. 183-194, 2002.

[27] E. Szliszka, G. Zydowicz, B. Janoszka, C. Dobosz, G. KowalczykZiomek, and W. Krol, "Ethanolic extract of Brazilian green propolis sensitizes prostate cancer cells to TRAIL-induced apoptosis," International Journal of Oncology, vol. 38, no. 4, pp. 941-953, 2011.

[28] T. Matsuno, S. K. Jung, Y. Matsumoto, M. Saito, and J. Morikawa, "Preferential cytotoxicity to tumor cells of 3,5-diprenyl-4hydroxycinnamic acid (artepillin C) isolated from propolis," Anticancer Research, vol. 17, no. 5 A, pp. 3565-3568, 1997.

[29] N. Oršolić, A. H. Knežević, L. Šver, S. Terzić, and I. Bašić, "Immunomodulatory and antimetastatic action of propolis and related polyphenolic compounds," Journal of Ethnopharmacology, vol. 94, no. 2, pp. 307-315, 2004.

[30] Y. J. Lee, H. C. Kuo, C. Y. Chu, C. J. Wang, W. C. Lin, and T. H. Tseng, "Involvement of tumor suppressor protein p53 and p38 MAPK in caffeic acid phenethyl ester-induced apoptosis of C6 glioma cells," Biochemical Pharmacology, vol. 66, no. 12, pp. 2281-2289, 2003.

[31] E. Szliszka, Z. P. Czuba, J. Bronikowska, A. Mertas, A. Paradysz, and W. Krol, "Ethanolic extract of propolis augments TRAILinduced apoptotic death in prostate cancer cells," EvidenceBased Complementary and Alternative Medicine, vol. 2011, Article ID 535172, 11 pages, 2011.
[32] D. E. Lange, H. C. Plagmann, A. Eenboom, and A. Promesberger, "Clinical methods for the objective evaluation of oral hygiene," Deutsche zahnarztliche Zeitschrift, vol. 32, no. 1, pp. 44-47, 1977.

[33] K. Beberhold, A. Sachse-Kulp, R. Schwestka-Poll, E. Horneckerand, and D. Ziebolz, "The orthodontic plaque index: an oral hygiene index for patients with multibracket appliances," Orthodontics, vol. 13, no. 1, pp. 94-99, 2012.

[34] H. Löe and J. Silness, "Periodontal disease in pregnancy I. prevalence and severity," Acta Odontologica Scandinavica, vol. 21, pp. 553-551, 1963.

[35] M. Magdalenic-Mestrovic and M. Bagatin, "An epidemiological study of orofacial clefts in Croatia 1988-1998," Journal of CranioMaxillo Facial Surgery, vol. 33, no. 2, pp. 85-90.

[36] L. L. Cheng, S. L. Moor, and C. T. C. Ho, "Predisposing factors to dental caries in children with cleft lip and palate: a review and strategies for early prevention," Cleft Palate-Craniofacial Journal, vol. 44, no. 1, pp. 67-72, 2007.

[37] G. Schultes, A. Gaggl, and H. Kärcher, "Comparison of periodontal disease in patients with clefts of palate and patients with unilateral clefts of lip, palate, and alveolus," The Cleft Palate Craniofacial Journal, vol. 36, no. 4, pp. 322-327, 1999.

[38] M. Stec, J. Szczepańska, J. Pypeć, and U. Hirschfelder, "Periodontal status and oral hygiene in two populations of cleft patients," The Cleft Palate Craniofacial Journal, vol. 44, no. 1, pp. 73-78, 2007.

[39] M. Klukowska, A. Bader, C. Erbe et al., "Plaque levels of patients with fixed orthodontic appliances measured by digital plaque image analysis," American Journal of Orthodontics and Dentofacial Orthopedics, vol. 139, no. 5, pp. e463-e470, 2011.

[40] B. Costa, J. E. De Oliveira Lima, M. R. Gomide, and O. P. Da Silva Rosa, "Clinical and microbiological evaluation of the periodontal status of children with unilateral complete cleft lip and palate," Cleft Palate-Craniofacial Journal, vol. 40, no. 6, pp. 585-589, 2003.

[41] H. Perdikogianni, W. Papaioannou, M. Nakou, C. Oulis, and L. Papagiannoulis, "Periodontal and microbiological parameters in children and adolescents with cleft lip and/or palate," International Journal of Paediatric Dentistry, vol. 19, no. 6, pp. 455-467, 2009.

[42] V. Dodwad and B. J. Kukreja, "Propolis mouthwash: a new beginning," Journal of Indian Society of Periodontology, vol. 15, no. 2, pp. 121-125, 2011.

[43] M. Tanasiewicz, M. Skucha-Nowak, M. Dawiec, W. Król, D. Skaba, and H. Twardawa, "Influence of hygienic preparations with a $3 \%$ content of ethanol extract of brazilian propolis on the state of the oral cavity," Advances in Clinical and Experimental Medicine, vol. 21, no. 1, pp. 81-92, 2012.

[44] P. I. Botushanov, G. I. Grigorov, and G. A. Aleksandrov, "A clinical study of a silicate toothpaste with extract from propolis," Folia medica, vol. 43, no. 1-2, pp. 28-30, 2001.

[45] E. M. R. Pereira, J. L. Cândido da Silva, F. F. Silva et al., "Clinical evidence of the efficacy of a mouth-wash containing propolis for the control of plaque and gingivitis: a phase II study," Evidence-Based Complementary and Alternative Medicine, vol. 2011, Article ID 750249, 7 pages, 2011.

[46] H. L. Ritz, "Microbial population shifts in developing human dental plaque," Archives of Oral Biology, vol. 12, no. 12, pp. 1561$1568,1967$.

[47] J. A. Aas, A. L. Griffen, S. R. Dardis et al., "Bacteria of dental caries in primary and permanent teeth in children and young 
adults," Journal of Clinical Microbiology, vol. 46, no. 4, pp. 14071417, 2008.

[48] J. O. Cisar, P. E. Kolenbrander, and F. C. McIntire, "Specificity of coaggregation reactions between human oral streptococci and strains of Actinomyces viscosus or Actinomyces naeslundii," Infection and Immunity, vol. 24, no. 3, pp. 742-752, 1979.

[49] P. D. Marsh, "Microbial ecology of dental plaque and its significance in health and disease," Advances in dental research, vol. 8, no. 2, pp. 263-271, 1994.

[50] M. A. Munson, A. Banerjee, T. F. Watson, and W. G. Wade, "Molecular analysis of the microflora associated with dental caries," Journal of Clinical Microbiology, vol. 42, no. 7, pp. 30233029, 2004.

[51] F. Özan, Z. Sümer, Z. A. Polat, K. Er, Ü. Özan, and O. Deger, "Effect of mouthrinse con-taining propolis on oral microorganisms and human gingival fibroblasts," European Journal of Dentistry, vol. 1, no. 4, pp. 195-201, 2007.

[52] O. K. Mirzoeva, R. N. Grishanin, and P. C. Calder, "Antimicrobial action of propolis and some of its components: the effects on growth, membrane potential and motility of bacteria," Microbiological Research, vol. 152, no. 3, pp. 239-246, 1997.

[53] Y. K. Park, M. H. Koo, J. A. S. Abreu, M. Ikegaki, J. A. Cury, and P. L. Rosalen, "Antimicrobial activity of propolis on oral microorganisms," Current Microbiology, vol. 36, no. 1, pp. 2428, 1998.

[54] H. Koo, M. F. Hayacibara, B. D. Schobel et al., "Inhibition of Streptococcus mutans biofilm accumulation and polysaccharide production by apigenin and tt-farnesol," Journal of Antimicrobial Chemotherapy, vol. 52, no. 5, pp. 782-789, 2003. 


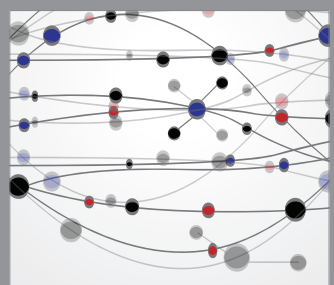

The Scientific World Journal
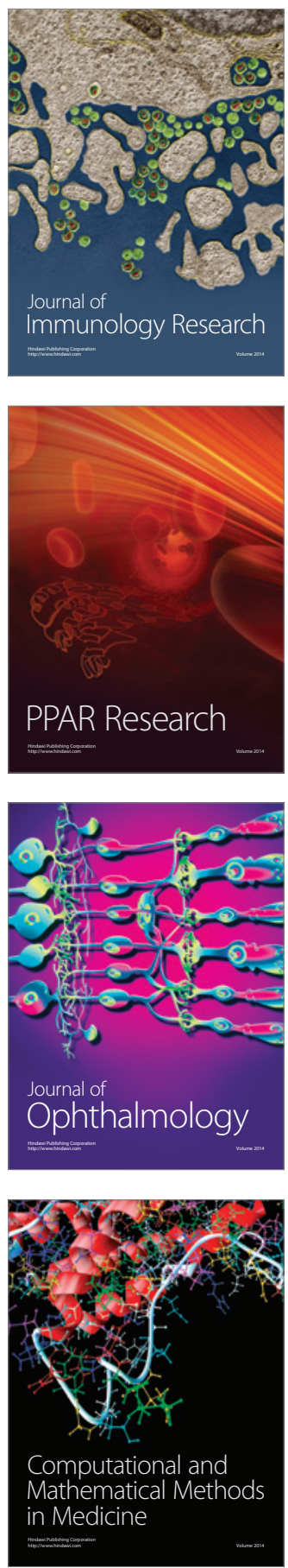

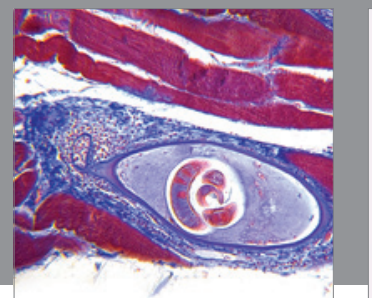

Gastroenterology

Research and Practice
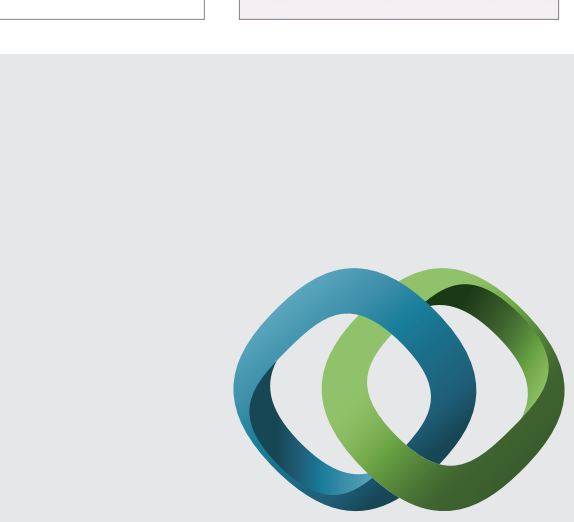

\section{Hindawi}

Submit your manuscripts at

http://www.hindawi.com
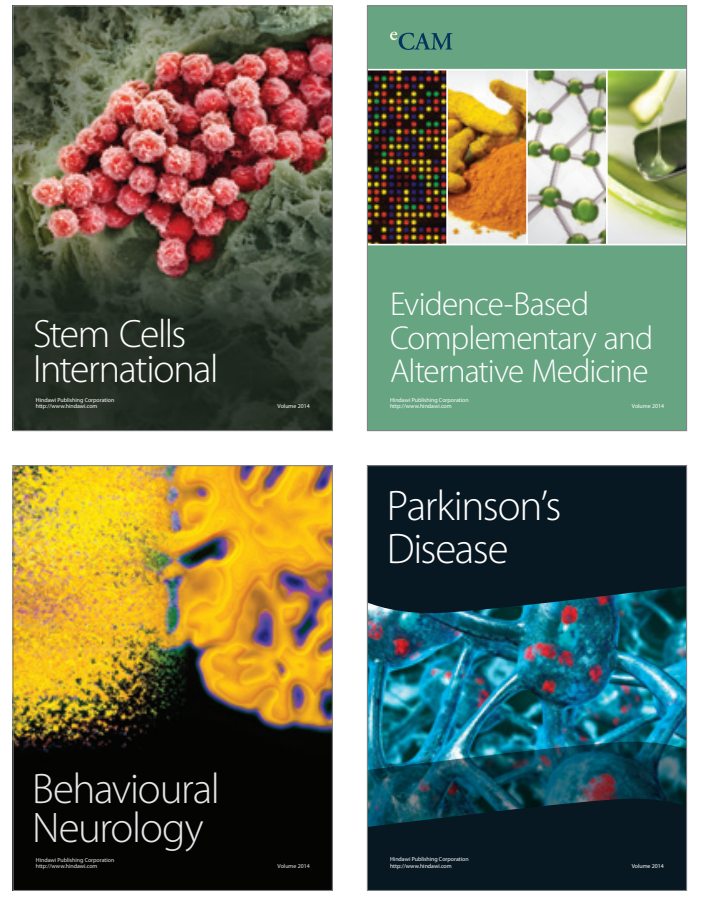
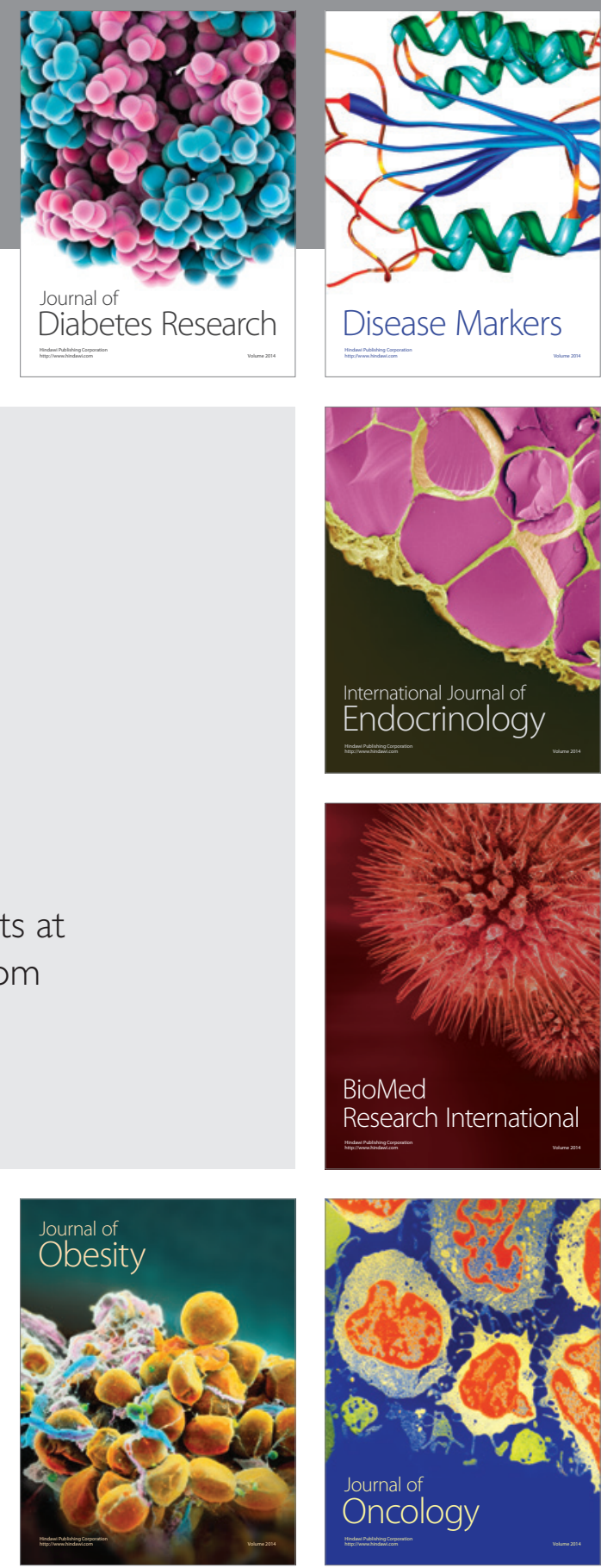

Disease Markers
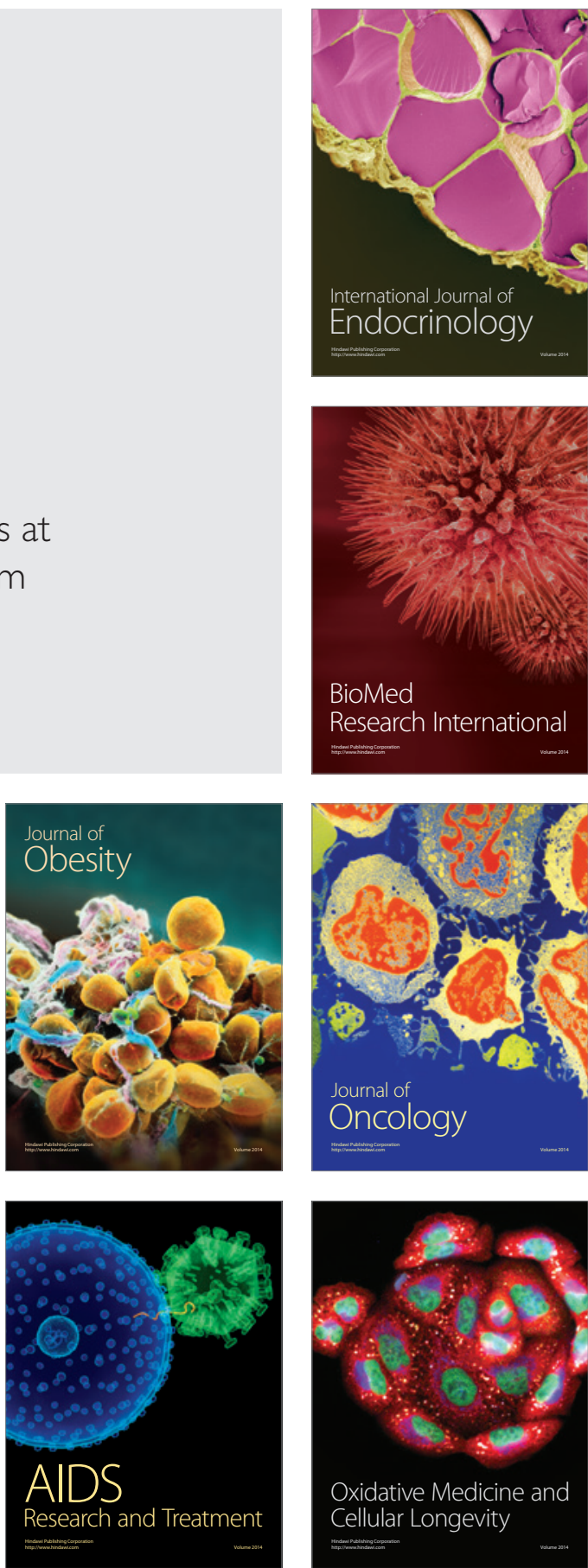